\title{
Pressure dependence of the electronic structure in kaolinite: A first-principles study
}

\author{
Zhi-Jie Fang*, ${ }^{*}$, Xiao-Shuai Zhai*, Zheng-Lin Li*, Rong-Jun Pan* and Man Mo* \\ * Guangxi University of Science and Technology, \\ Liuzhou 545006, China \\ $\dagger$ State Key Laboratory of Deep Geomechanics and Underground Engineering, \\ China University of Mining and Technology, Beijing 100083, China \\ ${ }^{\ddagger}$ nnfang@semi.ac.cn
}

\author{
Received 6 February 2017 \\ Revised 12 April 2017 \\ Accepted 17 April 2017 \\ Published 24 April 2017
}

\begin{abstract}
Using the first-principle methods, the pressure dependence of the electronic structure and band structure of kaolinite were studied within the local-density approximation. The calculated results show that pressure would chiefly alter the band structure of kaolinite, while pressure can have its main effect on the band gap of kaolinite. At $p=0.6 \mathrm{GPa}$, band structure of kaolinite first converts an indirect gap into a direct gap, and then recovers an indirect gap structure at $p=66.2 \mathrm{GPa}$ because CBM shift in the band structure is under high-pressure. The bond $\mathrm{Si}-\mathrm{O}$ is more stable than bond $\mathrm{Al}-\mathrm{O}$ under pressure, in addition, pressure has a significant effect on the inner hydroxyl bond of kaolinite and leads to a large variation of $\mathrm{H}-\mathrm{O}$ (inner) bond lengths. The calculated results will not only help to understand the electronic structure of kaolinite under pressure, but also provide theoretical guidance for deal with the safe problems of soft-rock tunnel engineering.
\end{abstract}

Keywords: First-principles method; pressure; kaolinite.

PACS Number(s): 91.60.Gf, 71.15.Mb, 91.60.-x

\section{Introduction}

Pressure is continually gaining more importance in soft-rock tunnel engineering, because of increasing mining depth and intensity, deep mining process due to high ground stress, high geothermal, high Karst water pressure and mining exploitation, which often cause the problems of soft-rock tunnel engineering and safety accidents in engineering practice. ${ }^{1,2}$ The engineering problem in soft-rock tunnel has increased

This is an Open Access article published by World Scientific Publishing Company. It is distributed under the terms of the Creative Commons Attribution 4.0 (CC-BY) License. Further distribution of this work is permitted, provided the original work is properly cited. 


\section{Z.-J. Fang et al.}

the demands for the better understanding of clay materials under pressure. ${ }^{3,4}$ In addition, the understanding of the pressure properties of the clays is also one main task for the researchers in both fields of geophysics and geomechanics. Among clay minerals, kaolinites have been extensively investigated because of not only their great technological importance in soft-rock tunnel engineering application, but also their interesting rich physical and chemical properties from the basic theoretical viewpoint. ${ }^{5}-7$ Many of the engineering safety problems are related to the pressure dependence of the properties of kaolinite. This is due to the fact that kaolinite has a kind of clay minerals with perfect 1:1 layer structure constituted by two different surfaces. For finite size, it is well known that high-pressure leads to more closely packed structure, which provides a way to alter the atomic and electronic structure in kaolinite. Thus, studying the pressure dependence of electronic structure and band structure is one of the most important topics in kaolinite research.

During the past decade, a large number of studies $^{8-15}$ on the physical and chemical properties of kaolinite have been performed. Nisar et al. studied the Optical gap and native point defects in kaolinite. $\frac{8}{}$ Then, Welch et al. investigated the highpressure behavior of kaolinite. $\cdot \frac{9}{}$ Recently, Etienne et al. tested the pore size and responses of kaolinite with different structures. $\frac{10}{}$ In contrast to the extensive experimental studies that have been carried out in the last decade, however, up to now, there have been very few theoretical works studying the physical and chemical properties of kaolinite. $\frac{8,16,17}{}$ In particular, an ab initio investigation of pressure properties of kaolinite is still lacking. Furthermore, it is worthwhile to introduce the theoretical work to explain the pressure properties of kaolinite from the basic viewpoints. Motivated by this observation, in this paper, a series of first-principles study pressure properties of kaolinite was reported by calculating its electronic structure, bond lengths, and density of states (DOS). The present first-principles results may be used to give a useful guide not only for the basic research on kaolinite, but also for the future technological applications of soft-rock tunnel engineering.

\section{Methods}

The kaolinite is an aqueous silicate mineral, in which water is present in the form of hydroxyl groups with molecular formula $\mathrm{Al}_{2} \mathrm{Si}_{2} \mathrm{O}_{9} \mathrm{H}_{4} \cdot{ }^{17}$ It is composed of a sheet of corner-sharing $\mathrm{SiO}_{4}$ tetrahedra linked, by common oxygen atoms parallel to the $c$-axis, to a sheet of edge-sharing $\mathrm{AlO}_{6}$ octahedra. The unit cell used in calculating the electronic structure includes 17 atoms, i.e. two $\mathrm{Al}$ atoms, two Si atoms, four hydrogen atoms and nine oxygen atoms (as shown in Fig. 1). The calculations for the kaolinite are based on density functional theory (DFT) within the localdensity approximation (LDA) ${ }^{18,19}$ as implemented in the vienna ab initio simulation package (VASP) ${ }^{20,21}$ code through the use of the projector augmented wave (PAW) pseudopotentials. ${ }^{22,23}$ All atomic positions are relaxed according to the calculated Helmann-Feynman force. Energy cutoff for the wave plan is set to $500 \mathrm{eV}$. The Monkhorst-Pack $k$-point is set to $5 \times 5 \times 5^{24,25}$ and is used to sample the Brillouin 


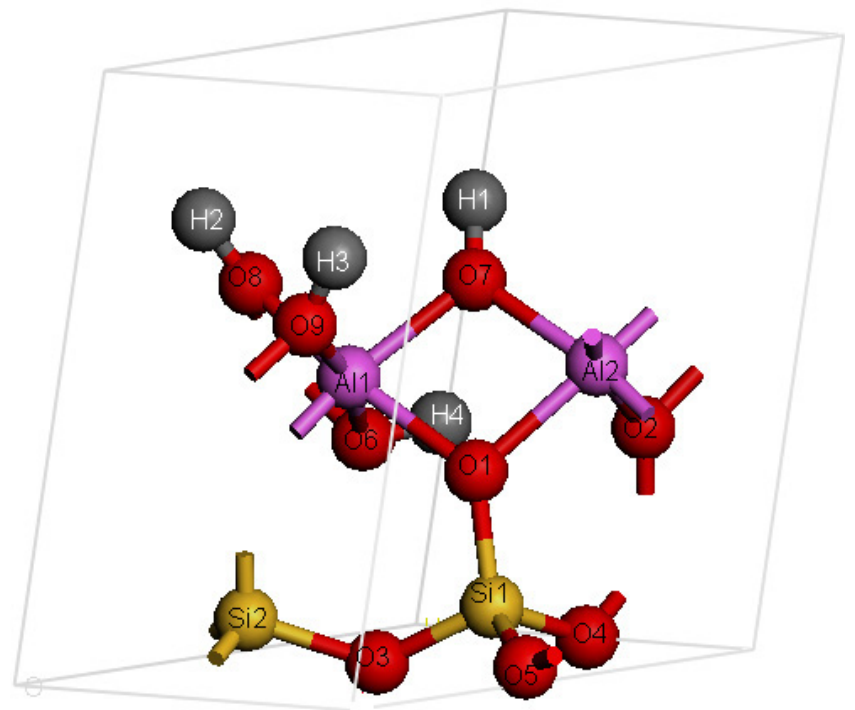

Fig. 1. (Color online) Unit cell of the kaolinite $\mathrm{Al}_{2} \mathrm{Si}_{2} \mathrm{O}_{9} \mathrm{H}_{4}$ containing 17 atoms, the red atoms are $\mathrm{O}$ atoms, the purple atoms are $\mathrm{Al}$ atoms, the yellow atoms are $\mathrm{Si}$ atoms, the gray atoms are $\mathrm{H}$ atoms.

zone. $3 s$ and $3 p$ of $\mathrm{Al}, 3 s$ and $3 p$ of $\mathrm{Si}, 1 s$ of $\mathrm{H}, 2 s$ and $2 p$ electrons of $\mathrm{O}$ are considered to be valence electrons in our calculation. The optimization of atomic geometries was performed via a conjugate gradient algorithm until residual force acting on atoms was less than $0.01 \mathrm{eV} \AA^{-1}$. The calculated structural parameters are $a=5.160(5.155) \AA, b=5.160(5.155) \AA, c=7.602(7.405) \AA$, compared with the available experimental data in parentheses. $\frac{26}{}$

\section{Results and Discussion}

Table 1 lists the calculated bond lengths in kaolinite under different pressures. In kaolinite, all oxygen atoms in crystal structure are inequivalent by symmetry, note that there are four different kinds of local coordinates for oxygen atoms, i.e. there are two oxygen atoms $\left(\mathrm{O}_{1}, \mathrm{O}_{2}\right)$ bridging the silicon ring system to the aluminium layer labeled as apical oxygens; the ring oxygens $\left(\mathrm{O}_{3}, \mathrm{O}_{4}, \mathrm{O}_{5}\right)$, which are members of the silicon ring system; the inner oxygen $\left(\mathrm{O}_{6}\right)$, which is attached to the inner hydrogen atom; and the interlayer oxygens $\left(\mathrm{O}_{7}, \mathrm{O}_{8}, \mathrm{O}_{9}\right)$, bonded to the interlayer hydrogens. From Table 1, at $p=0 \mathrm{GPa}, \mathrm{Si}-\mathrm{O}$ (ring) bond lengths are slightly longer than $\mathrm{Si}-\mathrm{O}$ (apical) bond lengths. Furthermore, it is obvious that $\mathrm{Al}-\mathrm{O}$ (apical) bond lengths are longer than the $\mathrm{Al}-\mathrm{O}$ (inner) and $\mathrm{Al}-\mathrm{O}$ (interlayer). It is well known that external pressure will push packed 1:1 layer structure, which will have a large effect on volume and lead to some obvious changes in bond lengths. As a result, one can see that, the inner $\mathrm{Al}-\mathrm{O}$ (apical) bond lengths significantly decrease from $1.96 \AA$ to $1.70 \AA$ with pressure increases, the similar trend can also be found for $\mathrm{Al}-\mathrm{O}$ (inner) 


\section{Z.-J. Fang et al.}

Table 1. The pressure dependence of the calculated bond lengths in optimized structure of kaolinite.

\begin{tabular}{lcccccc}
\hline \multicolumn{1}{c}{ Bonds } & $\begin{array}{c}0 \mathrm{GPa} \\
\text { bond } \\
\text { lengths }(\AA)\end{array}$ & $\begin{array}{c}20 \mathrm{GPa} \\
\text { bond } \\
\text { lengths }(\AA)\end{array}$ & $\begin{array}{c}40 \mathrm{GPa} \\
\text { bond } \\
\text { lengths }(\AA)\end{array}$ & $\begin{array}{c}60 \mathrm{GPa} \\
\text { bond } \\
\text { lengths }(\AA)\end{array}$ & $\begin{array}{c}80 \mathrm{GPa} \\
\text { bond } \\
\text { lengths }(\AA)\end{array}$ & $\begin{array}{c}100 \mathrm{GPa} \\
\text { bond } \\
\text { lengths }(\AA)\end{array}$ \\
\hline $\mathrm{Si}-\mathrm{O}_{\text {apical }}$ & 1.60 & 1.65 & 1.65 & 1.64 & 1.70 & 1.67 \\
$\mathrm{Si}-\mathrm{O}_{\text {ring }}$ & 1.63 & 1.62 & 1.61 & 1.59 & 1.55 & 1.55 \\
$\mathrm{Al}-\mathrm{O}_{\text {apical }}$ & 1.96 & 1.82 & 1.79 & 1.77 & 1.74 & 1.70 \\
$\mathrm{Al}-\mathrm{O}_{\text {inner }}$ & 1.90 & 1.79 & 1.75 & 1.73 & 1.76 & 1.73 \\
$\mathrm{Al}-\mathrm{O}_{\text {interlayer }}$ & 1.86 & 1.88 & 1.86 & 1.83 & 1.74 & 1.72 \\
$\mathrm{H}-\mathrm{O}_{\text {interlayer }}$ & 0.99 & 0.99 & 1.00 & 1.00 & 1.06 & 1.08 \\
$\mathrm{H}-\mathrm{O}_{\text {inner }}$ & 0.98 & 0.99 & 0.99 & 0.99 & 1.06 & 1.42 \\
\hline
\end{tabular}

and $\mathrm{Al}-\mathrm{O}$ (interlayer). However, for bond $\mathrm{Si}-\mathrm{O}$ (ring) and $\mathrm{Si}-\mathrm{O}$ (apical), which relate to silicon ring system, their bond lengths are slightly changing. Considering the lengths of hydroxyl groups, the calculation results have shown that, for $\mathrm{H}-\mathrm{O}$ (inner), the sharp increase of bond lengths (from $0.98 \AA$ to $1.42 \AA$ ) as the pressure increases from $0 \mathrm{Gpa}$ to $100 \mathrm{GPa}$ indicates that pressure has a large effect on the inner hydroxyl bond of kaolinite and leads to a large variation of $\mathrm{H}-\mathrm{O}$ (inner) bond lengths. From the calculated results above, the $\mathrm{Al}-\mathrm{O}$ bond length is longer than the $\mathrm{Si}-$ $\mathrm{O}$ bond length, the lengths of $\mathrm{Al}-\mathrm{O}$ bond became shorter significantly with the increase of pressure; whereas the bond lengths of $\mathrm{Si}-\mathrm{O}$ and $\mathrm{H}-\mathrm{O}$ band have relatively small change. These results indicate that bond $\mathrm{Si}-\mathrm{O}$ is more stable than bond $\mathrm{Al}-$ $\mathrm{O}$ under pressure. It can partially explain the reason that $\mathrm{Al}$ ions in kaolinite are easily replaced by some low-valent cation than Si ions.

Figure 2 shows the band structure of kaolinite under different pressures. The high-symmetry BZ points include $\Gamma(0,0,0), \mathbf{B}(0.5,0,0), \mathbf{F}(0,0.5,0)$ and $\mathbf{G}(0,0,0.5)$ which are marked in Fig. 2. Results for other pressure are also calculated; this paper does not list them here for the sake of conciseness. At $p=0$ GPa (see Fig. 2(a)), the valence-band maximum (VBM) of the kaolinite is at the $\mathbf{B}$ point and the conduction-band minimum $(\mathrm{CBM})$ is at the $\Gamma$ point, which shows that kaolinite has an indirect band gap with the gap width of $5.08 \mathrm{eV}$. Note that in Figs. 2(b) $-2(d)$, the band gap is now direct with both VBM and CBM at the $\Gamma$ point, whereas in Figs. 2(e) and 2(f), the band gap is indirect with VBM at the B point. These results indicate that the pressure would chiefly alter the conduct band structure of kaolinite. With increasing pressure, the shape of valence band remains similar, whereas the shape of conduct band has some changes because of the shifting up of conduction band.

In order to further understand these indirect-to-direct and direct-to-indirect band gap transitions, Table 2 lists the VBM and CBM for high-symmetry BZ points in kaolinite. Figure 3 also shows the energy of VBM and $\mathrm{CBM}$ as a function of the pressure for each high symmetric K point. One interesting result shows that the band structure of kaolinite is converting an indirect gap into a direct gap under tiny pressure, while the high-pressure could also change the band structure of kaolinite 

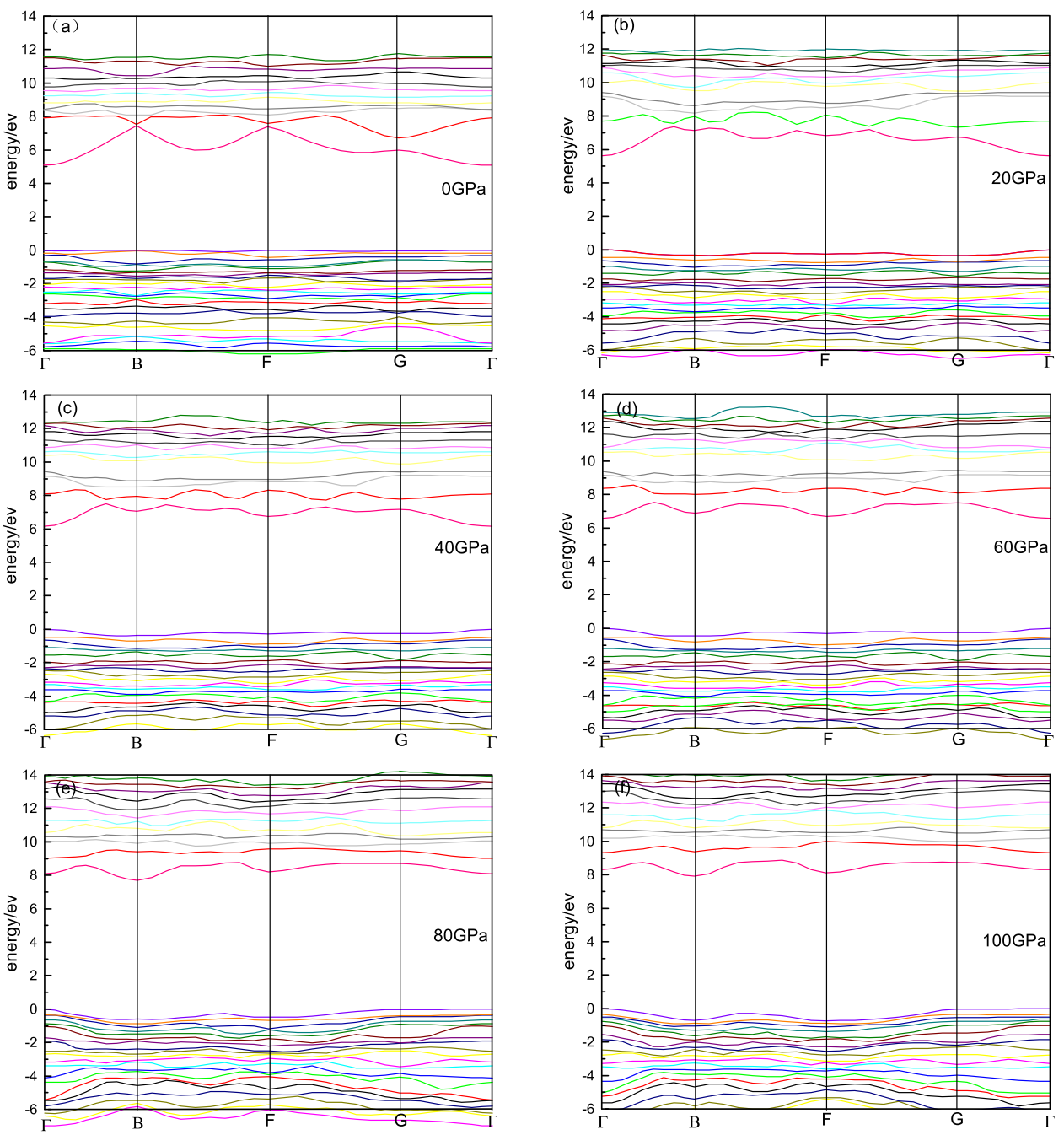

Fig. 2. (Color online) The change of band structure as functions of pressure for kaolinite. Band structure along the high-symmetry lines in the Brillouin zone. The Fermi energy is set at zero. (a), (b), (c), (d), (e) and (f) represent the pressure values of 0 Gpa, 20 Gpa, 40 Gpa, 60 Gpa, $80 \mathrm{Gpa}$ and $100 \mathrm{Gpa}$, respectively.

from a direct band gap to an indirect band gap. Comparing Fig. 2 with the data in Table 2, under pressure ranging from $0 \mathrm{GPa}$ to $0.5 \mathrm{GPa}$, one sees that kaolinite keeps the indirect gap, in which VBM is at $\mathbf{B}$ point and $\mathrm{CBM}$ at $\Gamma$ point. When $p=0.6 \mathrm{GPa}, \mathrm{VBM}$ changes from $\mathbf{B}$ point to $\Gamma$ point and the band gap becomes now direct with both VBM and CBM at the $\Gamma$ point. As the pressure increases, however, there are still two important transition points for CBM shift in the band structure. One is CBM change from $\Gamma$ point to $\mathbf{F}$ point occurring at $66.2 \mathrm{GPa}$, the other is CBM change from $\mathbf{F}$ point to $\mathbf{B}$ point occurring at $76.5 \mathrm{GPa}$. 


\section{Z.-J. Fang et al.}

Table 2. Under pressure, the VBM and CBM for high-symmetry BZ points in kaolinite.

\begin{tabular}{|c|c|c|c|c|c|c|c|c|c|c|c|}
\hline \multirow{2}{*}{$\begin{array}{c}\text { Pressure/ } \\
\text { GPa }\end{array}$} & & \multicolumn{4}{|c|}{ High-symmetry } & \multirow{2}{*}{$\begin{array}{c}\text { Pressure/ } \\
\text { GPa }\end{array}$} & & \multicolumn{4}{|c|}{ High-symmetry } \\
\hline & & $\Gamma$ & B & $\mathbf{F}$ & G & & & $\Gamma$ & B & $\mathbf{F}$ & G \\
\hline \multirow[t]{2}{*}{0} & CBM & 6.871 & 9.228 & 9.167 & 7.781 & 66.2 & CBM & 14.614 & 14.759 & 14.614 & 15.522 \\
\hline & VBM & 1.775 & 1.790 & 1.776 & 1.765 & & VBM & 7.923 & 7.462 & 7.591 & 7.663 \\
\hline \multirow[t]{2}{*}{0.5} & $\mathrm{CBM}$ & 6.977 & 9.341 & 9.274 & 7.886 & 66.3 & CBM & 14.618 & 14.762 & 14.617 & 15.527 \\
\hline & VBM & 1.863 & 1.864 & 1.854 & 1.854 & & VBM & 7.925 & 7.465 & 7.593 & 7.665 \\
\hline \multirow[t]{2}{*}{0.6} & $\mathrm{CBM}$ & 7.007 & 9.368 & 9.301 & 7.914 & 70 & CBM & 14.853 & 14.880 & 14.767 & 15.743 \\
\hline & VBM & 1.891 & 1.886 & 1.878 & 1.881 & & VBM & 8.075 & 7.612 & 7.734 & 7.818 \\
\hline \multirow[t]{2}{*}{10} & CBM & 9.482 & 11.239 & 11.030 & 10.471 & 76.4 & CBM & 15.200 & 15.026 & 15.014 & 16.064 \\
\hline & VBM & 4.131 & 3.904 & 4.002 & 3.680 & & VBM & 8.264 & 7.835 & 7.889 & 7.997 \\
\hline \multirow[t]{2}{*}{20} & $\mathrm{CBM}$ & 11.179 & 12.705 & 12.377 & 12.290 & 76.5 & CBM & 15.212 & 15.021 & 15.028 & 16.075 \\
\hline & VBM & 5.557 & 5.232 & 5.305 & 5.223 & & VBM & 8.264 & 7.846 & 7.884 & 7.994 \\
\hline \multirow[t]{2}{*}{30} & CBM & 12.123 & 13.330 & 13.012 & 13.195 & 80 & CBM & 16.327 & 15.933 & 16.440 & 16.929 \\
\hline & VBM & 6.215 & 5.877 & 5.958 & 5.930 & & VBM & 8.232 & 7.633 & 7.740 & 8.201 \\
\hline \multirow[t]{2}{*}{40} & CBM & 12.920 & 13.824 & 13.522 & 13.942 & 90 & CBM & 16.669 & 16.383 & 16.579 & 17.158 \\
\hline & VBM & 6.773 & 6.392 & 6.500 & 6.507 & & VBM & 8.464 & 7.781 & 7.783 & 8.431 \\
\hline \multirow[t]{2}{*}{50} & CBM & 13.606 & 14.227 & 13.959 & 14.584 & 100 & CBM & 17.080 & 16.683 & 16.877 & 17.515 \\
\hline & VBM & 7.252 & 6.828 & 6.963 & 6.994 & & VBM & 8.767 & 8.068 & 8.041 & 8.723 \\
\hline \multirow[t]{2}{*}{60} & $\mathrm{CBM}$ & 14.262 & 14.571 & 14.387 & 15.194 & 110 & $\mathrm{CBM}$ & 17.451 & 16.966 & 17.162 & 17.851 \\
\hline & VBM & 7.686 & 7.243 & 7.372 & 7.432 & & VBM & 9.053 & 8.340 & 8.293 & 8.997 \\
\hline
\end{tabular}

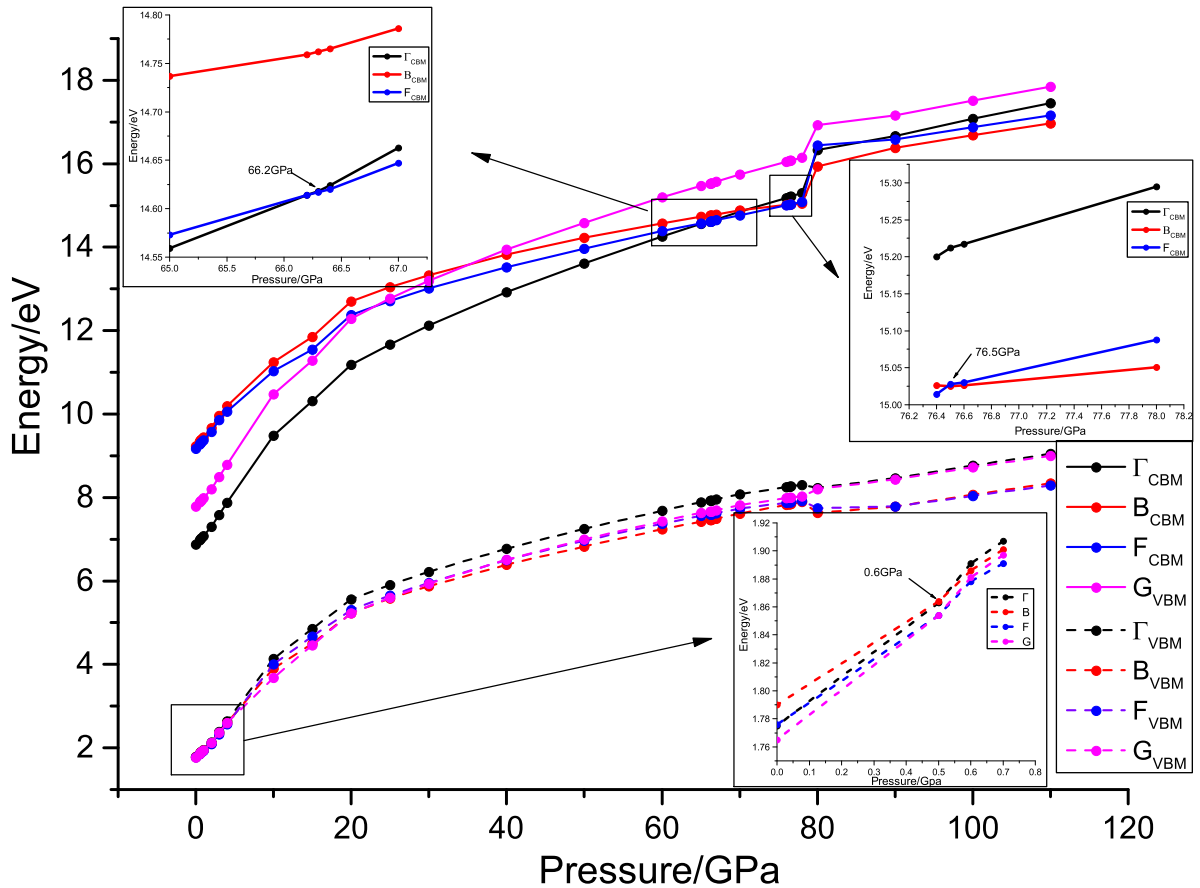

Fig. 3. (Color online) The energy of VBM and CBM as a function of the pressure for each high symmetric K point in kaolinite. 


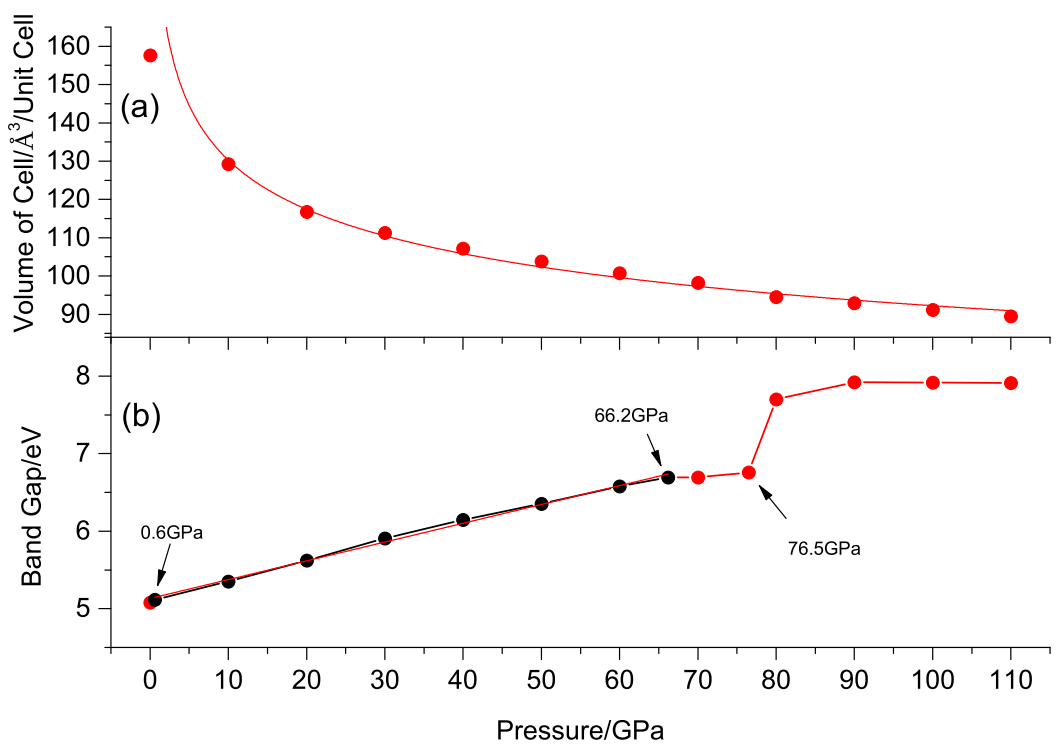

Fig. 4. (Color online) (a) and (b), respectively, represent the unit cell volume and band gap of kaolinite under pressure.

To obtain a more precise knowledge of pressure properties in kaolinite, furthermore, the volume (Fig. 4(a)) and values of $E_{g}$ (Fig. 4(b)) under pressure are shown in Fig. 4, respectively. From Fig. 4(a), one can see that the volume of kaolinite exponentially decreases as the corresponding pressure increases from $0 \mathrm{GPa}$ to $110 \mathrm{GPa}$, however, there is an obvious change in volume trend below $20 \mathrm{GPa}$. The main reason for this change is the distance between the kaolinite layers clearly reduced in the relative low-pressure range, whereas the chemical bond length shorted limitedly in the relative high-pressure range. Under pressure ranging from 0.6 GPa to 66.2 GPa, one can see from Fig. 4(b) that the corresponding band gap increases linearly with pressure and the pressure coefficient is 0.02425 . With the increasing of pressure, direct band gap widened gradually from $5.08 \mathrm{eV}(p=0 \mathrm{GPa})$ to $6.69 \mathrm{eV}$ $(p=70 \mathrm{GPa})$, which corresponds to an increase of the band gap by about $1.61 \mathrm{eV}$. As the pressure increases, the values of $E_{g}$ have a sharp increase from $6.69 \mathrm{eV}$ $(p=70 \mathrm{GPa})$ to $7.70 \mathrm{eV}(p=80 \mathrm{GPa})$ due to the transition from direct structure to indirect structure and this change is also illustrated in Fig. 3 for CBM shift in the band structure. Under high-pressure, the values of indirect band gap are stabilized when the pressure is greater than $80 \mathrm{GPa}$, which corresponds to the value of $E_{g}$ which is around $7.92 \mathrm{eV}$.

The orbital-resolved site-projected density of states (PDOS) of Al, Si, O and $\mathrm{H}$ atoms in the kaolinite unit cell are shown in Fig. 5. It is found that, at $p=0 \mathrm{GPa}$, the sharp peak of the PDOS of $\mathrm{O}$ (interlayer), $\mathrm{O}$ (apical) and $\mathrm{O}$ (inner) is very near from the VBM, which means these $\mathrm{O}$ atoms have the main contribution in VBM. Under pressure, it is found that, the peak of total DOS split into two parts from 

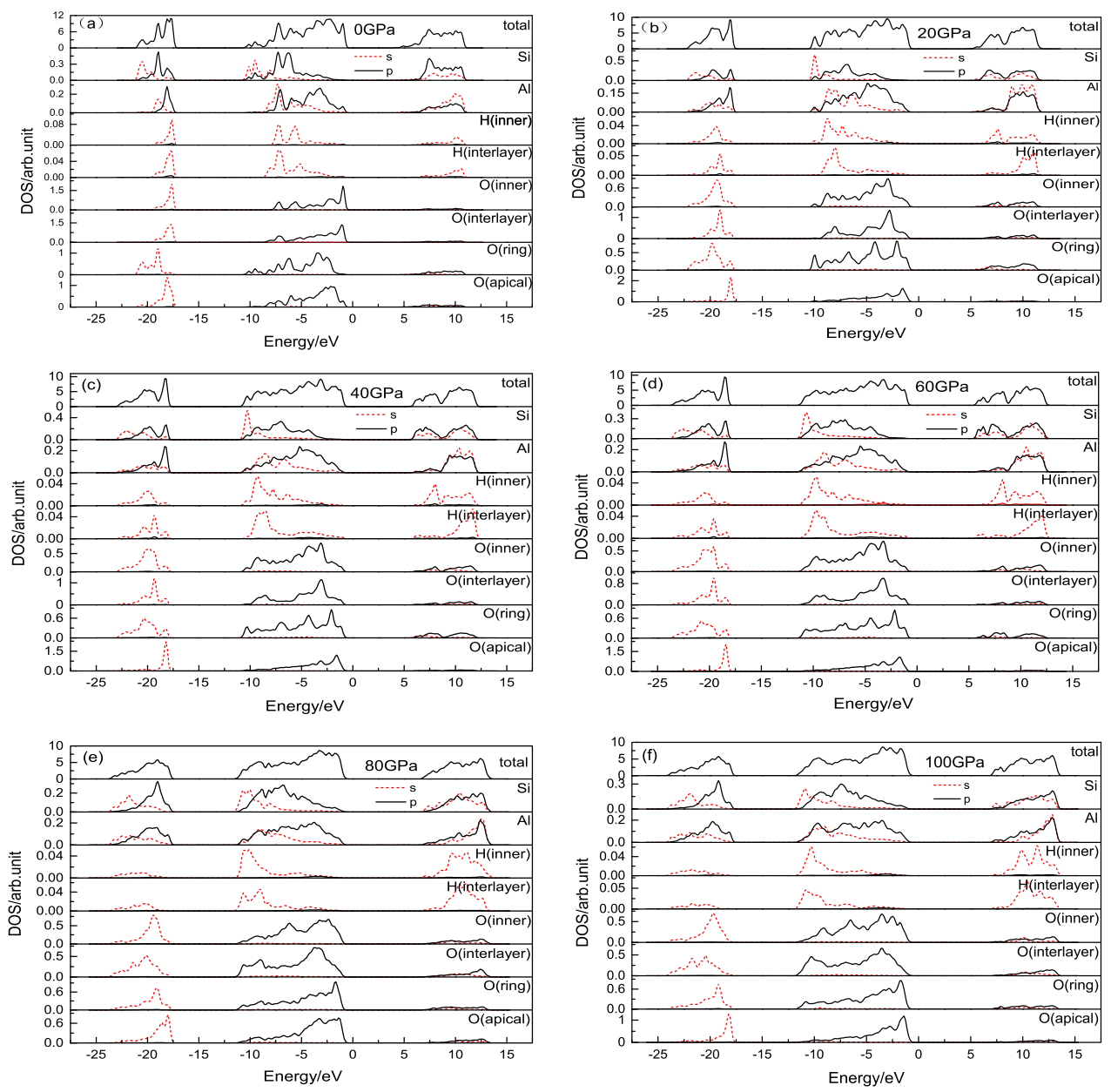

Fig. 5. (Color online) Orbital-resolved partial DOS for $\mathrm{Si}, \mathrm{Al}, \mathrm{O}$ and $\mathrm{H}$ atoms in kaolinite. (a), (b), (c), (d), (e) and (f), respectively, represent the stress value of 0 Gpa, 20 Gpa, 40 Gpa, $60 \mathrm{Gpa}, 80 \mathrm{Gpa}$ and $100 \mathrm{Gpa}$. The VBM is set at $\mathrm{O}$ eV.

$20 \mathrm{GPa}$ to $60 \mathrm{GPa}$ in conduction band region, the peak of DOS moves toward high energy region from $80 \mathrm{GPa}$ to $100 \mathrm{GPa}$ and the DOS split phenomenon disappeared. As the pressure increases, we note that the PDOS shapes of $\mathrm{Al}$, Si and four kinds of oxygen atoms remain similar, whereas there are some changes in PDOS of $\mathrm{H}$ atom. Specially, one can see that, the DOS peak height of $\mathrm{H}$ (interlayer) decreases from $0.07(p=0 \mathrm{GPa})$ to $0.04(p=100 \mathrm{GPa})$ in valence band region, which can result in the decreasing overlap of PDOS between $\mathrm{H}$ atom and $\mathrm{O}$ atom. The overlap phenomenon of PDOS between $\mathrm{H}$ atom and $\mathrm{O}$ atom is decreased with the increase of pressure, which also indicates that the bond strength of hydroxyl groups in kaolinite has been reduced. 


\section{Summary}

In summary, the electronic structures and pressure properties of kaolinite were studied by using first-principles calculations. The calculated results show that, at $p=0 \mathrm{GPa}$, the VBM of the kaolinite is at the $\mathbf{B}$ point and the CBM is at the $\Gamma$ point with the indirect band gap width of $5.08 \mathrm{eV}$. With the increasing of pressure, band gap widened from $5.08 \mathrm{eV}(p=0 \mathrm{GPa})$ to $7.92 \mathrm{eV}(p=100 \mathrm{GPa})$, which is mainly due to the shifting up of conduction band. At $p=0.6 \mathrm{GPa}$, band structure of kaolinite first converts an indirect gap into a direct gap, and then recovers an indirect gap structure at $p=66.2 \mathrm{GPa}$. Under pressure, bond strength of $\mathrm{Al}-\mathrm{O}$ is weaker than that of the $\mathrm{Si}-\mathrm{O}$ bond, and the bond strength of hydroxyl groups in kaolinite is reduced as pressure increases. It can be expected that the present firstprinciples results may be used to explain the various pressure behaviors of kaolinite from a microscopic viewpoint.

\section{Acknowledgments}

The work is funded by the National Natural Science Foundation of China (Grant Nos. 11464003 and 61464001) and Special Program for Applied Research on Super Computation of the NSFC-Guangdong Joint Fund (the second phase).

\section{References}

1. Z. B. Guo, J. Wang, X. W. Deng and L. Chen, Coal. Sci. Tech. 43 (2015) 40.

2. M. C. He, N. Xu and A. J. Yao, J. Chin. Univ. Mini. 10 (2000) 107.

3. B. Wang, Chin. Coal 37 (2011) 58.

4. Q. W. Lian and Z. Y. Chai, Min. Res. Dev. 31 (2011) 53.

5. T. Liu, X. F. Tian, Y. Zhao and T. Gao, Chin. Phys. B 19 (2010) 109101.

6. T. Liu and Y. Q. Chen, Chin. Phys. B 22 (2013) 027103.

7. M. C. He, J. Coal Sci. 17 (1996) 10.

8. J. Nisar, C. Arhammar, E. Jamstorp and R. Ahuja, Phys. Rev. B 84 (2011) 075120.

9. M. D. Welch, W. Montgomery, E. Balan and P. Lerch, Phys. Chem. Miner. 39 (2012) 143.

10. C. Y. Yu, K. C. Jun and Y. H. Wang, Eng. Geol. 202 (2016) 122.

11. P. H. Mercier and P. Y. Le, Eur. J. Mineral. 23 (2010) 401.

12. Y. H. Su, M. H. Zhao and X. M. Liu, Rock Soil Mech. 26 (2005) 728.

13. D. Levesque, J. J. Weis and G. N. Patey, Phys. Lett. A 66 (1978) 115.

14. C. Y. Zhou, X. S. Tan, Y. M. Deng, L. M. Zhang and J. H. Wang, Chin. J. Rock Mech. Eng. 24 (2005) 394.

15. D. L. Bish, Clays Clay Miner. 41 (1993) 738.

16. M. C. He, Z. J. Fang and P. Zhang, Chin. Phys. B 18 (2009) 2933.

17. M. C. He, J. Zhao and Z. J. Fang, Chin. Phys. B 21 (2012) 039101.

18. P. E. Blouchl, Phys. Rev. B 50 (1994) 17953.

19. G. Kresse and J. Joubert, Phys. Rev. B 59 (1999) 1758.

20. P. Hohenberg and W. Kohn, Phys. Rev. B 136 (1964) 864.

21. W. Kohn and L. J. Sham, Phys. Rev. 140 (1965) 1133.

22. G. Kresse and J. Furthmüller, Phys. Rev. B 54 (1996) 11169. 
23. G. Kresse and J. Furthmüller, Comput. Mater. Sci. 6 (1996) 15.

24. H. J. Monkhorst and J. D. Pack, Phys. Rev. B 13 (1976) 5188.

25. J. D. Pack and H. J. Monkhorst, Phys. Rev. B 16 (1977) 1748.

26. D. L. Bish and D. R. Von, Clays Clay Miner. 37 (1989) 289. 